() Open Access Full Text Article

ORIGINAL RESEARCH

\title{
Amantadine reduces glucagon and enhances insulin secretion throughout the oral glucose tolerance test: central plus peripheral nervous system mechanisms
}

\author{
This article was published in the following Dove Press journal: \\ Diabetes, Metabolic Syndrome and Obesity:Targets and Therapy \\ I December 2009
}

Number of times this article has been viewed

\author{
Fuad Lechin' \\ Bertha van der Dijs' \\ Betty Pardey-Maldonado' \\ Jairo E Rivera' \\ Marcel E Lechin² \\ Scarlet Baez' \\ 'Department of Physiological Sciences, \\ Sections of Neuroendocrinology, \\ Neuropharmacology, and \\ Neurochemistry, Instituto de Medicina \\ Experimental, Faculty of Medicine, \\ Universidad Central de Venezuela, \\ Caracas, Venezuela; ${ }^{2}$ Department \\ of Internal Medicine, Texas A \& M \\ Health Science Center, College \\ of Medicine, TX, USA
}

Objective: The purpose of the trial was to examine the effects of amantadine, a N-methyl-D-aspartate (NMDA) antagonist, on the oral glucose tolerance test (OGTT) plus insulin, glucagon and neurotransmitters circulating levels. Previous findings showed that hyperinsulinism and type 2 diabetes are positively associated with neural sympathetic and adrenal sympathetic activities, respectively. These peripheral sympathetic branches depend on the pontine $\left(\mathrm{A}_{5}\right.$-noradrenergic $)$ and the rostral ventrolateral $\left(\mathrm{C}_{1}\right.$-adrenergic $)$ medullary nuclei. They are excited by glutamate axons which act at NMDA postsynaptic receptors.

Research design and methods: One OGTT plus placebo and one OGTT plus oral amantadine test were carried out two weeks apart in 15 caucasic normal voluntary humans. Noradrenaline, adrenaline, dopamine, plasma-free serotonin, platelet serotonin, glucose, glucagon, and insulin were measured throughout the 180-minute testing period.

Results: Maximal reductions of plasma glucose and glucagon plus exacerbated insulin rises were significantly greater throughout the oral glucose plus amantadine test than those registered throughout the oral glucose plus placebo challenge. The above findings were paralleled by greater than normal noradrenaline/adrenaline plasma ratio increases. In addition, maximal reductions of the platelet serotonin and plasma serotonin circulating values contrasted with the normal rises of these parameters, always registered during the glucose load plus placebo challenge.

Conclusion: This study supports the theory that amantadine might be a powerful antidiabetic tool and could be added to the therapeutic arsenal against type 2 diabetes.

Keywords: glucagon, insulin, type 2 diabetes, sympathetic nervous system, blood serotonin, blood catecholamines, amantadine

\section{Introduction}

The interaction between alpha- and beta-islet cells is responsible for plasma glucose homeostasis. ${ }^{1}$ Predominance of the former and the latter are responsible for hyperglycemia ${ }^{2-4}$ and hypoglycemia, ${ }^{4,5}$ respectively. In addition, this binomial peripheral crosstalk is modulated by several physiological factors which include both peripheral neuroendocrine and central nervous system (CNS) mechanisms. ${ }^{6,7}$ However, this physiological stability can be disrupted by many stressor factors such as exercise and restraint, ${ }^{8,9}$ neuropharmacological agents such as tianeptine (enhancer of serotonin uptake), ${ }^{10}$ doxepin (inhibitor of serotonin uptake), ${ }^{11}$ or dopaminergic-blocking agents (such as sulpiride, haloperidol). ${ }^{12,13}$ Quantitative and/or qualitative changes of the above factors might lead to hyper- or hypoglycemic disorders. Most research work dealing 
with this issue has investiged the peripheral mechanisms involved in the alpha-cell versus beta-cell crosstalk (endocrine, gastrointestinal, and neuroautonomic); however, little research work has been devoted to the understanding of the CNS circuitry responsible for the alpha- versus beta-cells interaction and/or CNS versus peripheral autonomic nervous system (ANS) parameters. The investigation of such crosstalk might redound in findings able to lead to the outlining of adequate neuropharmacological therapeutical strategies addressed to normalize the peripheral disorders responsible for the alpha-cells $\leftrightarrow$ beta-cells imbalance.

Evidence have demonstrated that insulin excites neural sympathetic activity ${ }^{14,15}$ while glucagon excites adrenal sympathetic activity. ${ }^{16-18}$ In addition, both sympathetic branches of the peripheral ANS depend on the $\mathrm{A}_{5}$ pontomedullary nucleus that releases noradrenaline (NA) ${ }^{19}$ and the $\mathrm{C}_{1}$ medullary nuclei which secrete adrenaline (Ad). ${ }^{20-24}$ Furthermore, both CNS nuclei interchange direct inhibitory axons whose neurotransmitters act at post-synaptic alpha- 2 receptors, which crowd both nuclei. ${ }^{18-25}$ Finally, experimental evidence has demonstrated that secretion of both peripheral hormones (insulin and glucagon) would depend on the interaction between two opposite neuroendocrine circuits. According to the above, we decided to investigate the effect of amantadine, a glutamic acid (N-methyl-D-aspartate [NMDA]) antagonist, which inhibits the $\mathrm{C}_{1}$ (Ad) but not the $\mathrm{A}_{5}$ (NA) nuclei, and provokes absolute reduction of plasma adrenaline concentration when administered to normal subjects during fasting conditions. ${ }^{26-31}$

\section{Methods}

One oral glucose tolerance test (OGTT) plus placebo and one OGTT plus oral amantadine $(100 \mathrm{mg})$ test were carried out two weeks apart in 15 caucasic normal voluntary humans (seven males and eight females), whose ages ranged from 25 to 58 years (mean \pm standard error of mean $[\mathrm{SEM}]=38.4 \pm 7.2$ ) (Tables $1-3)$. The study was conducted in accordance with the guidelines in the Declaration of Helsinki. Written informed consent was obtained after the purpose, nature and potential risks had been explained to the subjects. The experimental protocol was approved by the Ethical Committee of FUNDAIME. All subjects were within $10 \%$ of ideal body weight, and none had undergone abdominal surgery or were taking any medications. None of the subjects had physical or psychiatric illness. Subjects were rated on a modified Hamilton Depression Rating Scale for depression and all of them completed the self-rating Beck
Depression Inventory ${ }^{11}$ in order to discard subjects with depression. Pregnancy, lactation, smoking and/or alcoholism factors also excluded subjects.

\section{Analytical methods}

The assessment of circulating neurotransmitters throughout the OGTT + placebo test carried out according to the present protocol ratified other previously published research studies. ${ }^{10,11}$ Noradrenaline, adrenaline, dopamine, plasma free serotonin (f5-HT), platelet serotonin (p5-HT), glucose, glucagon, and insulin were measured throughout the 180 -minute testing period. For all parameters, the samples were assayed in duplicate and all determinations were made simultaneously. We used reverse-phase, ion-pair high performance liquid chromatography with electrochemical detection for the detection of monoamines. Optimization of chromatographic conditions and attainment of adequate quantification parameters allowed us to maximize sensitivity and reproducibility.

All tests were performed on recumbent subjects after 14 hours of fasting. A heparinized venous catheter was inserted into a forearm vein at least 30 minutes before beginning the tests. Blood samples were collected at 0, 30, 60, 90, 120, and 180 minutes. Each subject drank a $30 \%$ glucose solution $(1 \mathrm{~g} / \mathrm{kg}$ of ideal body weight) plus placebo or an oral dose of amantadine $(100 \mathrm{mg}=$ one capsule). Blood for catecholamines and serotonin assays was transferred to plastic tubes, each containing $20 \mathrm{mg}$ of EDTA plus $10 \mathrm{mg}$ of sodium bisulphite/ml of solution. The tubes were carefully inverted and placed on ice. The blood was promptly centrifuged at $600 \mathrm{rpm}$ for 15 minutes at $4^{\circ} \mathrm{C}$ in order to obtain platelet-rich plasma. Two milliliters of platelet-rich plasma, obtained for determination of platelet serotonin (p5-HT), were taken and stored at $-70^{\circ} \mathrm{C}$ until assayed. The remaining blood was again centrifuged at 7,000 rpm. The supernatant, platelet-poor plasma, was divided into four portions for determination of insulin, glucagon, catecholamines and free serotonin (f5-HT), after which all portions were stored at $-70^{\circ} \mathrm{C}$ until assayed. Plasma glucose samples were immediately processed.

\section{Reagents and standards}

Noradrenaline, adrenaline, dopamine, serotonin creatinine sulphate, dihydroxybenzylamine, sodium octyl sulphate, dibutylamine, acid-washed aluminium oxide, $\mathrm{Na}_{2} \mathrm{HPO}_{4}$, citric acid and EDTA were purchased from Sigma-Aldrich (St. Louis, MO, USA). Microfilters were purchased from Whatman Inc. (Florham Park, NY, USA) through Merck 
Table I Correlations found during the oral glucose tolerance + placebo test performed in I5 normal voluntary human (seven males and eight females)

\begin{tabular}{|c|c|c|c|c|c|c|}
\hline & \multicolumn{6}{|c|}{ Periods } \\
\hline & $0 \mathrm{~min}$ & $30 \mathrm{~min}$ & $60 \mathrm{~min}$ & $90 \mathrm{~min}$ & $120 \mathrm{~min}$ & $180 \mathrm{~min}$ \\
\hline NA vs Ad & ns & ns & ns & ns & ns & ns \\
\hline NA vs DA & ns & ns & $0.203^{*}$ & $0.256^{*}$ & $0.32 I^{* *}$ & $0.293^{* *}$ \\
\hline Ad vs DA & ns & ns & ns & ns & ns & ns \\
\hline NA vs glycemia & ns & ns & $-0.221 *$ & $-0.325^{* *}$ & $-0.442 * *$ & $-0.456 * *$ \\
\hline DA vs glycemia & ns & ns & $-0.211 *$ & $-0.247^{*}$ & $-0.354 * *$ & $-0.376 * *$ \\
\hline Ad vs glycemia & ns & ns & ns & ns & ns & ns \\
\hline NA vs $\mathrm{p} 5-\mathrm{HT}$ & ns & ns & ns & ns & ns & ns \\
\hline Ad vs $\mathrm{p} 5-\mathrm{HT}$ & ns & ns & ns & ns & ns & ns \\
\hline DA vs $\mathrm{p} 5-\mathrm{HT}$ & ns & ns & ns & ns & ns & ns \\
\hline p5-HT vs glycemia & ns & ns & ns & ns & ns & ns \\
\hline NA vs insulin & ns & ns & $0.325^{*}$ & $0.411 * *$ & $0.40 I * *$ & $0.397 * *$ \\
\hline DA vs insulin & ns & ns & $0.214^{*}$ & $0.222^{*}$ & $0.216^{*}$ & $0.217^{*}$ \\
\hline Ad vs insulin & ns & ns & ns & ns & ns & ns \\
\hline p5-HT vs insulin & ns & ns & $-0.212 *$ & -0.223 & $-0.23 I^{*}$ & $-0.214 *$ \\
\hline NA vs glucagon & ns & ns & $-0.299 *$ & $-0.297^{*}$ & $-0.365 * *$ & $-0.377^{* *}$ \\
\hline DA vs glucagon & ns & ns & ns & $-0.288^{*}$ & $-0.322^{*}$ & $-0.315^{*}$ \\
\hline Ad vs glucagon & ns & ns & ns & ns & ns & ns \\
\hline P5-HT vs glucagon & ns & ns & ns & ns & ns & ns \\
\hline NA vs HR & ns & ns & ns & ns & ns & ns \\
\hline Ad vs HR & ns & ns & ns & ns & ns & ns \\
\hline DA vs HR & ns & ns & ns & ns & ns & ns \\
\hline NA/Ad vs SBP & ns & ns & ns & ns & ns & ns \\
\hline NA/Ad vs DBP & ns & ns & $0.207^{*}$ & $0.214^{*}$ & $0.221 *$ & $0.218^{*}$ \\
\hline DA vs SBP & ns & ns & ns & ns & ns & ns \\
\hline DA vs DBP & ns & ns & $-0.213^{*}$ & $-0.210^{*}$ & $-0.220 *$ & $-0.222 *$ \\
\hline
\end{tabular}

Notes: Levels of significance, $* P<0.05 ; * P<0.01$.

Abbreviations: NA, noradrenaline; Ad, adrenaline; DA, dopamine; 5 5-HT, platelet serotonin; $f 5-H T$, plasma serotonin; $H R$, heart rate; $S B P$, systolic blood pressure; DBP, diastolic blood pressure.

S.A. (Caracas, Venezuela). Acetonitrile and 2-propanol were obtained from Merck, S.A. Glass-distilled water was de-ionized and filtered through a Milli-Q reagent grade water system (Millipore, Bedford, MA, USA). Solvents were filtered through a $0.2 \mu \mathrm{m}$ Millipore filter and were vacuum de-aerated. Standard solutions $(1 \mathrm{mmol} / \mathrm{L})$ were prepared in $0.1 \mathrm{~mol} / \mathrm{L}$ perchloric acid and diluted to the desired concentration.

\section{Equipment}

Liquid chromatography was performed using Waters 515 HPLC pump (Waters Corporation, Milford, MA. USA) equipped with a Rheodyne valve injector $7125 \mathrm{i}$, which was fitted with a $50 \mu \mathrm{L}$ sample loop (Rheodyne; Berodine, Berkeley, CA, USA). A $15 \mathrm{~cm} \times 4.6 \mathrm{~mm}$ inner diameter Discovery C18 column packed with octadecylsilane $5 \mu \mathrm{m}$ particles was preceded by a column prefilter of $2 \mu \mathrm{m}$ porosity, both from Supelco/Sigma-Aldrich. The detection system was a Waters 460 Electrochemical Detector (Waters Corporation). The potential of the working electrode (glass carbon) was set at $+0.61 \mathrm{~V}$ versus the $\mathrm{Ag}-\mathrm{AgCl}$ reference electrode for the detection of catecholamines and $0.70 \mathrm{~V}$ versus the $\mathrm{Ag}-\mathrm{AgCl}$ for the detection of indolamines. The chromatograms were registered and quantified with Empower software (Waters Corporation). The results were corrected for the volume of EDTA added.

\section{Analytical assays}

\section{Plasma catecholamines}

The assay was performed by extraction of the catecholamines onto $20 \mathrm{mg}$ of alumina followed by their elution with $200 \mu \mathrm{L}$ of $1.0 \mathrm{~mol} / \mathrm{L} \mathrm{HClO}_{4}$ using regenerated cellulose 
Table 2 Correlations found during the oral glucose tolerance + amantadine test performed in I 5 normal voluntary human (seven males and eight females)

\begin{tabular}{|c|c|c|c|c|c|c|}
\hline & \multicolumn{6}{|c|}{ Periods } \\
\hline & $0 \mathrm{~min}$ & $30 \mathrm{~min}$ & $60 \mathrm{~min}$ & $90 \mathrm{~min}$ & $120 \mathrm{~min}$ & $180 \mathrm{~min}$ \\
\hline NA vs Ad & ns & ns & ns & ns & ns & ns \\
\hline NA vs DA & ns & ns & $0.368 * *$ & $0.377^{* *}$ & $0.405 * *$ & $0.426 * *$ \\
\hline Ad vs DA & ns & ns & ns & ns & ns & ns \\
\hline NA vs glycemia & ns & ns & $-0.267^{*}$ & $-0.338 * *$ & $-0.422^{* *}$ & $-0.439 * *$ \\
\hline DA vs glycemia & ns & ns & $-0.332 *$ & $-0.365^{*}$ & $-0.41 \mathrm{I} * *$ & $-0.395 * *$ \\
\hline Ad vs glycemia & ns & ns & ns & ns & ns & ns \\
\hline NA vs $\mathrm{p} 5-\mathrm{HT}$ & ns & ns & $-0.244 *$ & $-0.332 *$ & $-0.326^{*}$ & $-0.299 *$ \\
\hline Ad vs p5-HT & ns & ns & ns & ns & ns & ns \\
\hline DA vs p5-HT & ns & ns & $-0.237^{*}$ & $-0.314 *$ & $-0.333^{*}$ & ns \\
\hline p5-HT vs glycemia & ns & ns & $0.244^{*}$ & $0.338^{*}$ & $0.352^{*}$ & $0.34 I^{*}$ \\
\hline NA vs insulin & ns & ns & $0.211 *$ & $0.253^{*}$ & $0.324 * *$ & $0.323 * *$ \\
\hline DA vs insulin & ns & ns & $0.199 *$ & $0.218^{*}$ & $0.235^{*}$ & $0.239 *$ \\
\hline Ad vs insulin & ns & ns & ns & ns & ns & ns \\
\hline p5-HT vs insulin & ns & ns & $-0.368 * *$ & $-0.387 * *$ & $-0.359 * *$ & $-0.37 \mid$ ** \\
\hline NA vs glucagon & ns & ns & $-0.318^{*}$ & $-0.409 * *$ & $-0.396 * *$ & $-0.402 * *$ \\
\hline DA vs glucagon & ns & ns & $-0.297^{*}$ & $-0.346 *$ & $-0.40 I^{* *}$ & $-0.4 \mathrm{II} * *$ \\
\hline Ad vs glucagon & ns & ns & ns & ns & ns & ns \\
\hline P5-HT vs glucagon & ns & ns & ns & $0.363^{*}$ & $0.402^{* *}$ & $0.416^{* *}$ \\
\hline NA vs HR & ns & ns & ns & ns & ns & ns \\
\hline Ad vs HR & ns & ns & ns & ns & ns & ns \\
\hline DA vs HR & ns & ns & ns & ns & ns & ns \\
\hline NA/Ad vs SBP & ns & ns & ns & ns & ns & ns \\
\hline NA/Ad vs DBP & ns & ns & $0.232^{*}$ & $0.229^{*}$ & $0.239 *$ & $0.24 I^{*}$ \\
\hline DA vs SBP & ns & ns & ns & ns & ns & ns \\
\hline DA vs DBP & ns & ns & $-0.218^{*}$ & $-0.222 *$ & $-0.219^{*}$ & $-0.23 \mathrm{I} *$ \\
\hline
\end{tabular}

Notes: Levels of significance, $* P<0.05 ; * * P<0.01$.

Abbreviations: NA, noradrenaline; Ad, adrenaline; DA, dopamine; p5-HT, platelet serotonin; f5-HT, plasma serotonin; HR, heart rate; SBP, systolic blood pressure; DBP, diastolic blood pressure.

microfilters $0.2 \mu \mathrm{m}$ pore size (Whatman Inc.). We calibrated the instrument with standard plasma. After incubation with acid-washed aluminum oxide, a plasma pool of free catecholamines was processed similarly to plasma samples, but $20 \mu \mathrm{L}$ of a standard solution of noradrenaline, adrenaline, and dopamine $(50,25$, and $25 \mathrm{ng} / \mathrm{mL}$, respectively) were added to the plasma pool. Both the standard plasma and the sample plasma were supplemented with $20 \mu \mathrm{L}$ of internal standard (100 ng/mL of dihydroxybenzylamine). The mobile phase was $\mathrm{KH}_{2} \mathrm{PO}_{4} 6.8045 \mathrm{~g} / \mathrm{L}$, EDTA $0.100 \mathrm{~g} / \mathrm{L}$ and di-N-butylamine $100 \mu \mathrm{l} / \mathrm{L}$. Sodium octyl sulphate was added as ion-pair agent in a concentration of $0.6125 \mathrm{~g} / \mathrm{L}$ with the $\mathrm{pH}$ adjusted to 5.6 . The flow rate was $0.400 \mathrm{~mL} / \mathrm{min}$. The sensitivity of this method for noradrenaline, adrenaline and dopamine was $6.4,5.8$, and $2.0 \mathrm{pg} / \mathrm{mL}$, respectively.
The intraassay coefficients of variation were $2.8 \%, 4.0 \%$, and $4.0 \%$, respectively. The inter-assay coefficients of variation were $6.7 \%, 4.5 \%$, and $4.3 \%$, respectively.

\section{Plasma indolamines}

After sonication of platelet-rich plasma to disrupt the platelets (Ultrasonic Liquid Processor, model 385; Heat Systems Ultrasonics Inc., Farmingdale, NY, USA), both platelet-rich and platelet-poor plasma were processed in the same way: $200 \mu \mathrm{L}$ of $3.4 \mathrm{~mol} / \mathrm{L}$ perchloric acid and $50 \mu \mathrm{l}$ of 5-hydroxy-tryptophan solution $(114.5 \mu \mathrm{g} / \mathrm{mL})$ as internal standard, were added to $1 \mathrm{~mL}$ of plasma vortexed and centrifuged at $10,000 \mathrm{rpm}$ for 15 minutes at $4^{\circ} \mathrm{C}$. The supernatant was filtered through a $0.22 \mu \mathrm{m}$ membrane (Millipore) and $10 \mu \mathrm{L}$ was injected into the column. Calibration runs were 
Table 3 Changes in SBP, DBP, and HR induced in 15 normal voluntary healthy humans (eight males and seven females) when one OGTT plus placebo and one OGTT plus amantadine tests were carried out two weeks apart

\begin{tabular}{|c|c|c|c|c|}
\hline & \multicolumn{2}{|c|}{$\begin{array}{l}\text { OGTT + placebo } \\
\text { test }\end{array}$} & \multicolumn{2}{|c|}{$\begin{array}{l}\text { OGTT + amantadine } \\
\text { test }\end{array}$} \\
\hline & $0 \mathrm{~min}$ & $180 \mathrm{~min}$ & $0 \mathrm{~min}$ & $180 \mathrm{~min}$ \\
\hline HR (beats/min) & $71 \pm 5$ & $66 \pm 7^{*}$ & $73 \pm 7$ & $65 \pm 8 * *$ \\
\hline $\mathrm{SBP}(\mathrm{mm} \mathrm{Hg})$ & $127 \pm 8$ & $122 \pm 3$ & $127 \pm 8$ & $124 \pm 7$ \\
\hline $\mathrm{DBP}(\mathrm{mm} \mathrm{Hg})$ & $73 \pm 5$ & $76 \pm 4^{*}$ & $71 \pm 6$ & $88 \pm 4 * *$ \\
\hline
\end{tabular}

Notes: Results are expressed as mean \pm SEM. $* P<0.05 ; * * P<0.01$ (versus 0 min value).

Abbreviations: DBP, diastolic blood pressure; HR, heart rate; OGTT, oral glucose tolerance test; SBP, systolic blood pressure; SEM, standard error of mean.

generated by spiking blank platelet-poor plasma with $50 \mu \mathrm{L}$ of a solution containing $5-\mathrm{HT}(10 \mu \mathrm{g} / \mathrm{mL})$ and $50 \mu \mathrm{L}$ of 5-hydroxy-tryptophan $(114.5 \mu \mathrm{g} / \mathrm{mL})$. This standard plasma was processed in the same manner as the samples. The mobile phase was citric acid $3.8424 \mathrm{~g} / \mathrm{L}$, sodium acetate $4.1015 \mathrm{~g} / \mathrm{L}$, EDTA $0.100 \mathrm{~g} / \mathrm{L}$, di-N-butylamine $100 \mu \mathrm{l} / \mathrm{L}$, and $30 \mathrm{ml} / \mathrm{L}$ of 2-propanol. Sodium octyl sulphate was added as ion-pair agent in a concentration of $4.25 \mathrm{mg} / \mathrm{L}$ with a $\mathrm{pH}$ of 5.0. The flow rate was $0.610 \mathrm{~mL} / \mathrm{min}$. The sensitivity of the method for serotonin was $0.1 \mathrm{ng} / \mathrm{mL}$. The intra-assay coefficients of variation for p5-HT and f5-HT were $6.2 \%$ and $8.7 \%$, respectively.

\section{Plasma insulin}

This was determined in duplicate by insulin ELISA kit (Cosmo Bio, Carlsbad, CA, USA).

\section{Plasma glucagon}

Plasma glucagon was determined by radioimmunoassay (RIA) kit GL-32K (Linco Research; Millipore). In our hands, the intraassay variation was $4.5 \pm 1.2$ and $11.1 \pm 2.8$ for the interassay variation.

\section{Plasma glucose}

Plasma glucose concentration was measured in duplicate with a glucose oxidase method ${ }^{32}$ using Glucose Analyzer II (Beckman Instruments, Fullerton, CA, USA).

\section{Statistical methods}

Results are presented as the mean \pm SEM. Statistical significance was set at $* P<0.05 ; * * P<0.02 ; * * * P<0.01$ (versus 0 min value). Multivariate ANOVA with repeated measurements, paired t test, and correlation coefficients (exploratory factor analysis) were used. dBase Stats $^{\mathrm{TM}}$ (Ashton Tate, Chicago, IL, USA) and StatView
$\mathrm{SE}+$ Graphics (SAS Institute, Cary, NC, USA) were used for statistical analyses.

\section{Results Oral glucose + placebo test}

Suppression of plasma glucagon concentration was observed throughout the test with a nadir of $40.0 \pm 5.0 \mathrm{pg} / \mathrm{mL}$ at the 90-minute period. Maximal rise of glucose was registered at the 30-minute period, whereas minimal mean values were reached at the 180-minute period (Figure 1). Noradrenaline and platelet serotonin circulating parameters showed significant and sustained rises which paralleled insulin increases and opposed plasma glucose reductions. Significant reduction of adrenaline values were registered throughout the test. Dopamine did not show significant changes (Figure 2). In addition to the above, although both noradrenaline and platelet serotonin concentrations were raised after the oral glucose load, the noradrenaline/p5-HT ratio showed significant falls throughout the OGTT (Figure 3). No significant f5-HT changes were registered throughout the test. All of our subjects fell asleep and displayed rapid eye movements (REM) during OGTT, especially accentuated at the 90-minute and 180-minute periods.

\section{Oral glucose + amantadine test}

Subjects showed drowsiness but not REM sleep throughout the test. Adrenaline showed maximal and sustained decreases throughout the post-amantadine periods. Conversely, significant and sustained noradrenaline plus dopamine rises opposed the adrenaline falls. In addition, abrupt fall of f5-HT and p5-HT parameters were also registered throughout the OGTT + amantadine challenge (Figure 4).

Maximal and sustained reductions of both plasma glucose and glucagon were observed. Small and sustained but significant insulin rises were registered throughout postglucose + amantadine periods (Figure 1). Maximal fall of systolic blood pressure and heart rate, were also observed throughout the post-drug + glucose periods.

\section{Discussion}

The results obtained from the present study demonstrated that the addition of a small dose of amantadine (100 mg) to the OGTT was able to enhance the insulinogenic plus hypoglycemic effects normally triggered by the ingested sugar. These effects were paralleled by the enhancement of the normal neural sympathetic overactivity, always registered throughout the OGTT as well as by the accentuation of 


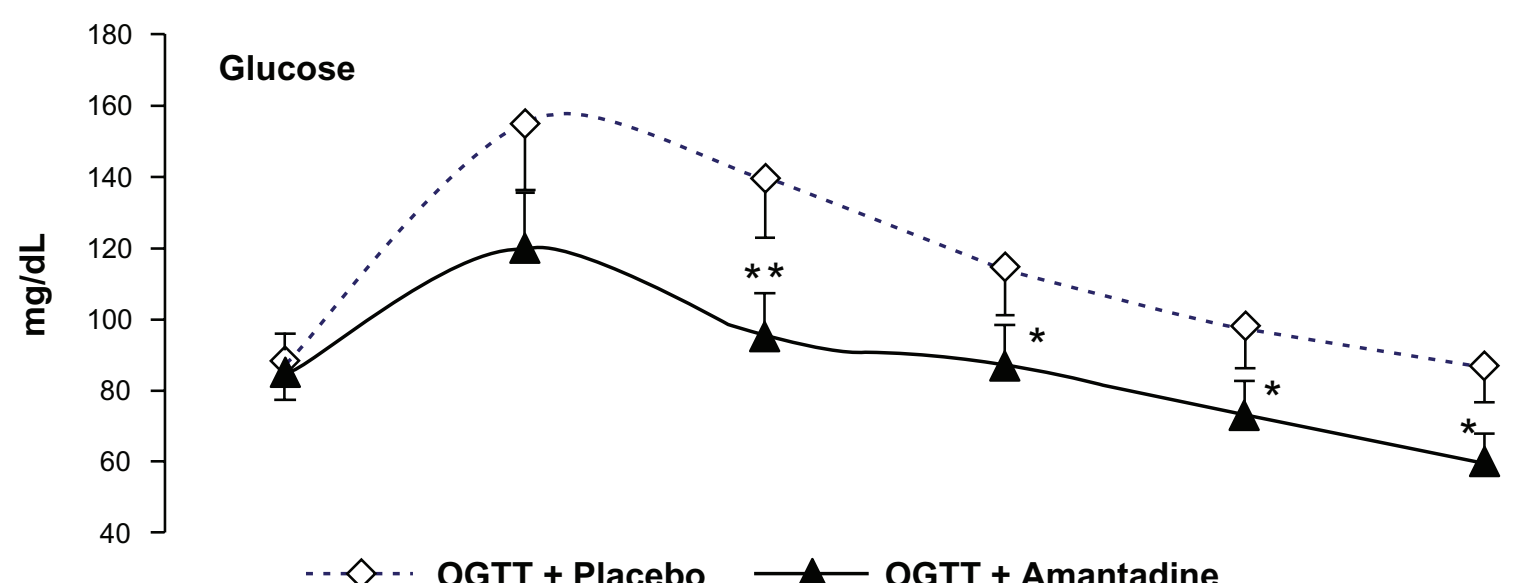

\section{Glucagon}
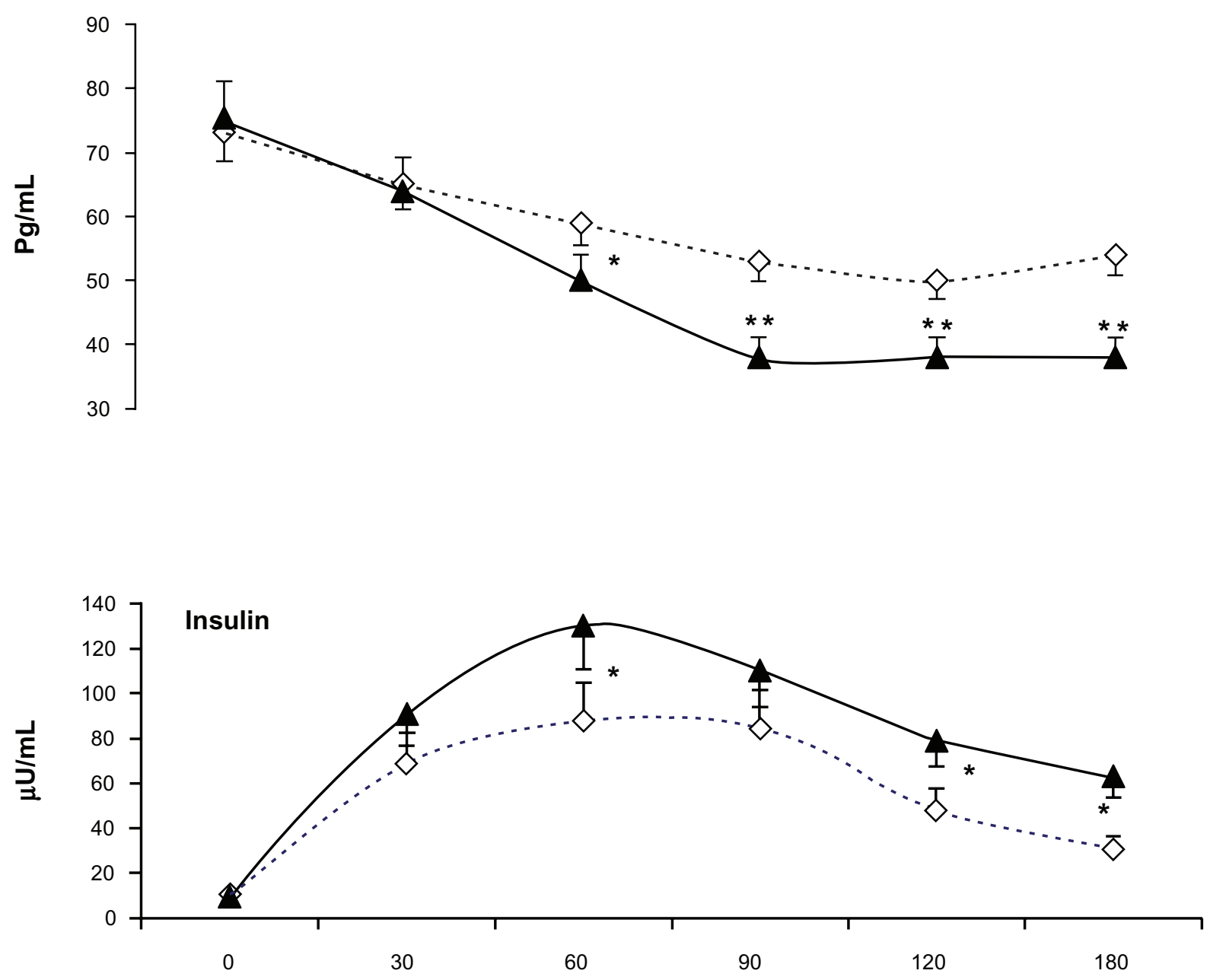

Minutes

Figure I The addition of an oral dose of amantadine $(100 \mathrm{mg})$ to an oral glucose load potentiated both the glucose and glucagon reductions and increased postprandial insulin levels in 15 normal healthy subjects (seven males and eight females), whose ages ranged from 25 to 58 years (mean \pm SEM $=38.4 \pm 7.2$ ).

Notes: Values are expressed as mean \pm SEM $* P<0.05 ; * * P<0.02$ (versus 0 min value).

Abbreviation: SEM, standard error of mean. 

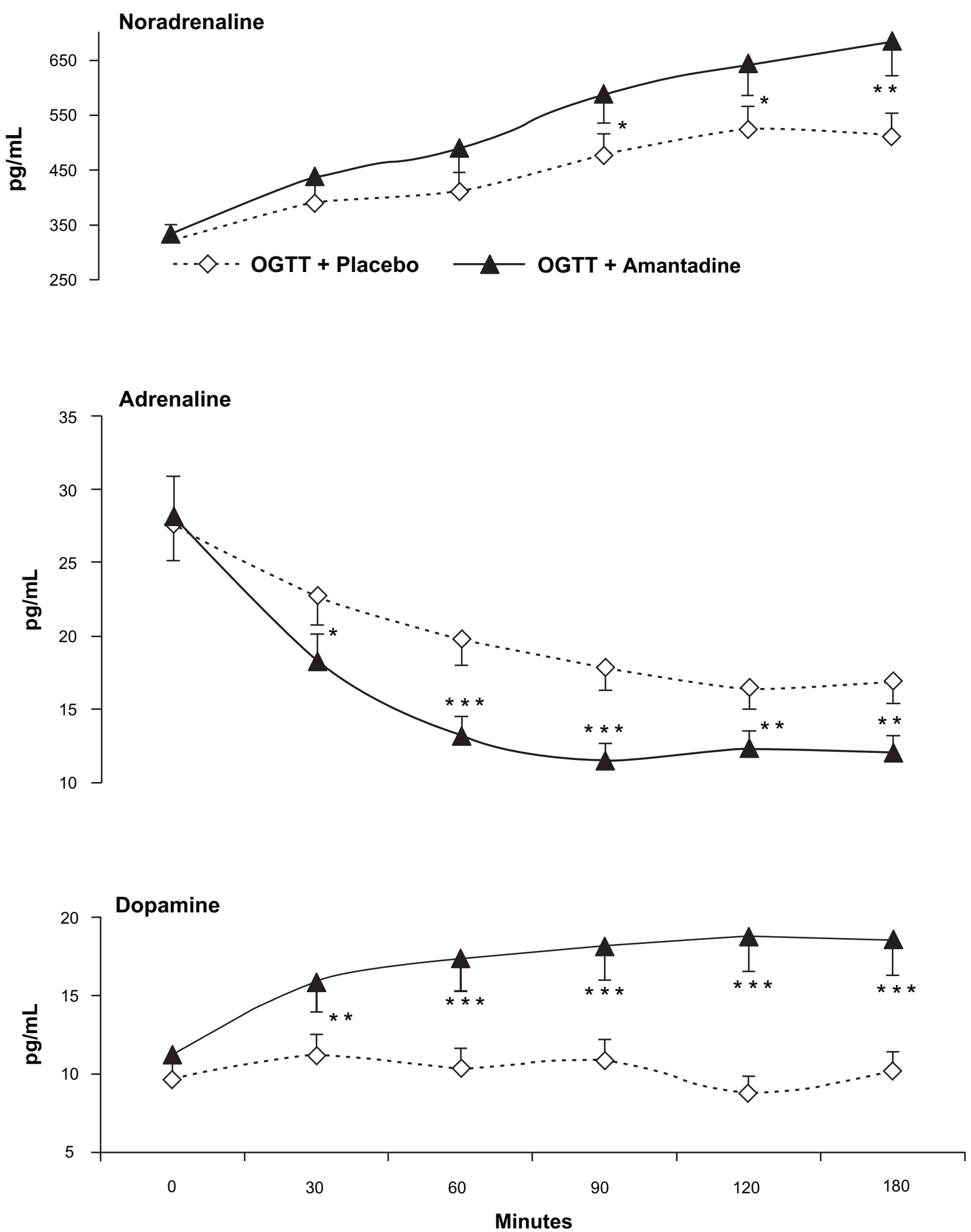

Figure 2 The addition of an oral dose of amantadine $(100 \mathrm{mg})$ to an oral glucose load enhanced the normal noradrenaline and dopamine rises, always observed throughout the OGTT + placebo test. Conversely, maximal reduction of adrenaline opposed the former rises.

Notes: $\mathrm{N}=15$ (seven males and eight females), whose ages ranged from 25 to 58 years (mean $\pm S E M=38.4 \pm 7.2$ ). Values are expressed as mean $\pm S E M$. $* P<0.05$; $* * P<0.02$; $* * * P<0.01$ (versus 0 min value).

Abbreviations: OGTT, oral glucose tolerance test; SEM, standard error of mean. 

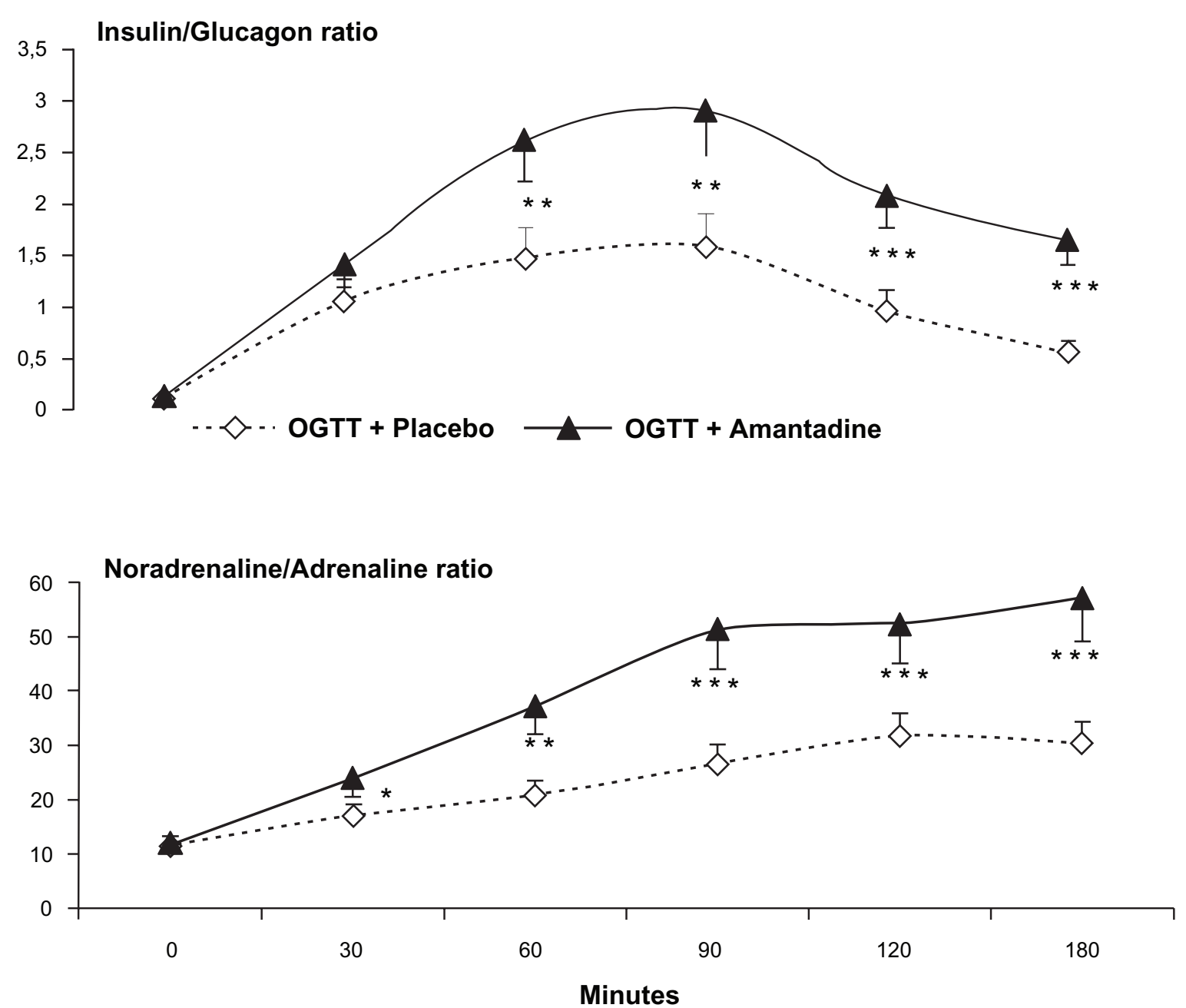

Figure 3 The insulin/glucagon ratio as well as the noradrenaline/adrenaline ratio showed paralleled increases throughout the oral glucose tolerance test when I00 mg of oral amantadine was given to 15 normal healthy subjects (seven males and eight females), whose ages ranged from 25 to 58 years (mean \pm SEM $=38.4 \pm 7.2$ ).

Notes: Values are expressed as mean \pm SEM. $* P<0.05$; $* * P<0.02$ (versus 0 min value).

Abbreviation: SEM, standard error of mean.

the fall of the adrenaline plus glucagon plasma levels that occurs after an oral glucose load. Both insulin and glucagon cross the blood-brain barrier and excite the $\mathrm{A}_{5}$ (NA) $)^{14,17,33,34}$ and the $C_{1}(\mathrm{Ad})^{16,33-36}$ pontomedullary nuclei, respectively. The former is responsible for the peripheral neural (noradrenergic) sympathetic activity whereas the latter excites adrenal sympathetic glands, which secrete $80 \%$ of adrenaline. The fact that glutamatergic axons innervate and excite the $\mathrm{C}_{1}$ (Ad) but not the $\mathrm{A}_{5}$ (NA) neurons (by acting at NMDA receptors) explains why amantadine (a NMDA antagonist) interferes with the adrenal but not with the neural sympathetic activity. With respect to this, experimental evidences obtained from our laboratory, demonstrated that a small dose of amantadine (administered without glucose) provokes absolute minimization of the adrenaline plasma concentration. $^{24,29}$
In addition to all the above, some other factors should be considered in order to understand the ability by amantadine to annul the glucagon-induced excitatory effect at the $\mathrm{CNS} \mathrm{C}_{1}(\mathrm{Ad})+$ peripheral adrenal sympathetic axis, which would explain its insulinogenic + hypoglycemic effects. For instance, the drug was able to provoke maximal reduction of both plasma serotonin and platelet serotonin concentration. This circulating indolamine exerts an inhibitory effect at the beta-cell level and in addition is able to excite alpha-cells, which secrete glucagon. ${ }^{37-41}$ Furthermore, plasma serotonin is able to excite the adrenal glands, ${ }^{39,42}$ directly. Thus, the reduction of plasma serotonin plus platelet serotonin circulating values registered in the present study should be taken into account in order to understand the hypoglycemic effect triggered by amantadine, when this drug was added to an oral glucose load. 

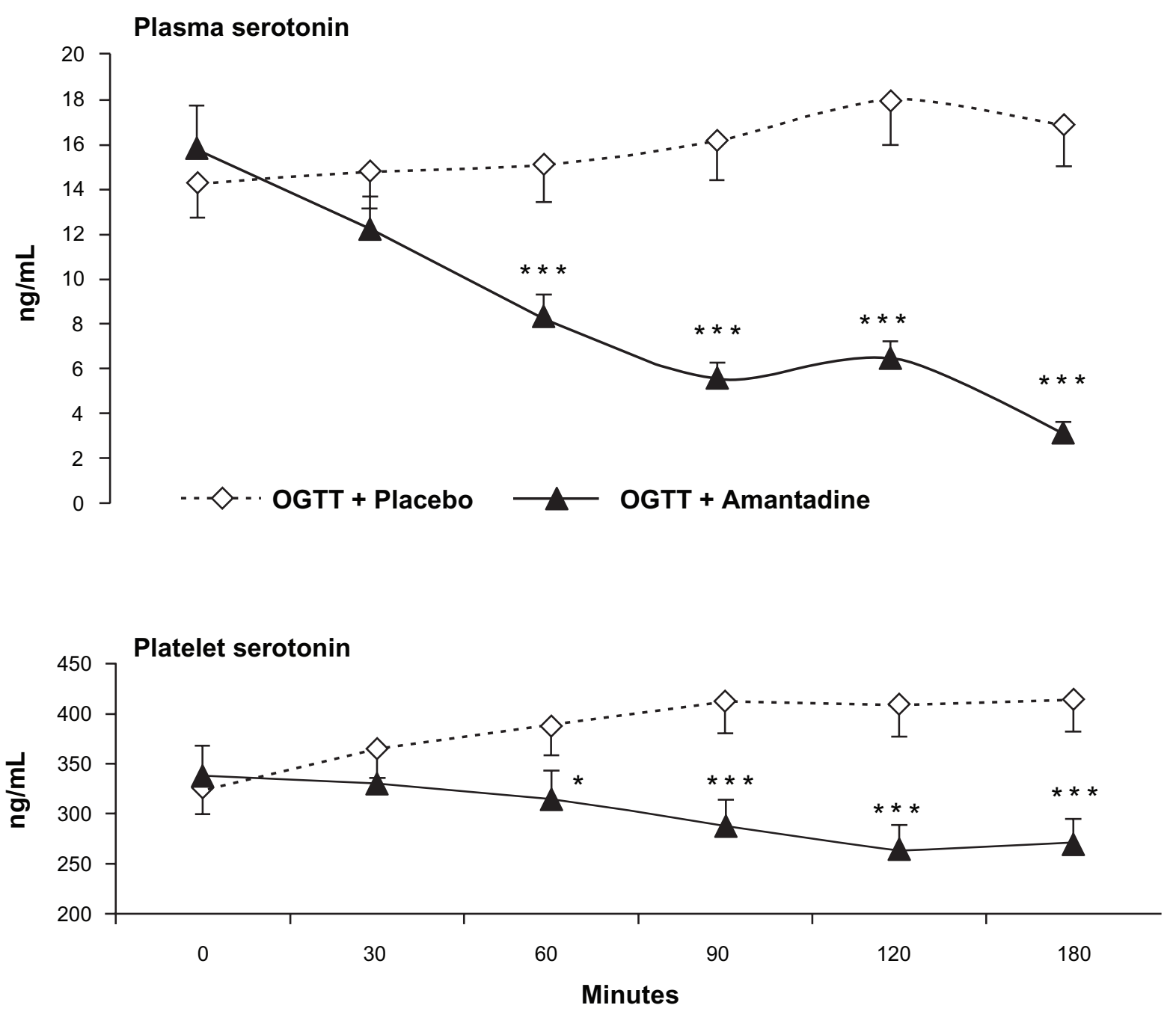

Figure 4 Both platelet serotonin ( $\mathrm{p5}-\mathrm{HT}$ ) and plasma serotonin ( $\mathrm{f5}-\mathrm{HT})$ showed maximal decreases throughout the test when an oral dose of amantadine ( 100 mg) was added to an oral glucose load. These findings contrast with the significant rises of both parameters observed throughout the oral glucose load + placebo challenge.

Notes: $\mathrm{N}=15$ (seven males and eight females), whose ages ranged from 25 to 58 years (mean $\pm S E M=38.4 \pm 7.2$ ). Values are expressed as mean $\pm S E M$. $* P<0.05$; $* * * P<0.0$ I (versus 0 min value).

Abbreviation: SEM, standard error of mean.

The minimization of the circulating serotonin concentration (plasma serotonin + platelet serotonin) registered in the present study might find an explanation in the overwhelming neural sympathetic over adrenal sympathetic activity triggered by amantadine. It should be remembered that the release of serotonin from the enterochromaffin cells depends on the excitatory parasympathetic drive which should be interfered by the enhancement of the neural sympathetic activity (noradrenaline/adrenaline ratio) registered in this study. ${ }^{40,43-48}$ The minimization of the plasma acetylcholine concentration, which competes with serotonin for the platelet uptake, fits well with the maximal reduction of the plasma serotonin values registered during the post amantadine periods. This postulation is in accordance with the maximal fall of systolic blood pressure and heart rate, observed throughout the post-drug periods. Both cardiovascular parameters are positively correlated with the peripheral adrenal sympathetic activity greatly minimized in the present study because of the inhibition by amantadine of the $\mathrm{C}_{1}(\mathrm{Ad})$ medullary nuclei.

In addition to the above, it has been shown that other drugs like tianeptine, which also minimizes plasma serotonin concentration is able to enhance plasma insulin secretion. ${ }^{10}$ This fact should be attributed to the direct inhibitory effect exerted by this indolamine at the beta-cell level.

The enhancement of the noradrenaline/adrenaline plasma ratio registered in the present study indicates that the overwhelming neural sympathetic activity annulled the peripheral adrenal sympathetic branch. This peripheral neuroautonomic profile depends on the absolute 
predominance of the $A_{5}$ (NA) pontomedullary nucleus over the $\mathrm{C}_{1}$ (Ad) medullary nuclei..$^{24,49}$ The above CNS $\mathrm{A}_{5}$ (NA) versus $\mathrm{C}_{1}$ (Ad) predominance which redounded in the peripheral neural sympathetic plus beta-cells hyperactivity merits some additional comments. With respect to this, it should be known that sympathetic nerves innervate and excite alpha-cells by acting at alpha- 2 receptors but not beta-cells. ${ }^{20-22,50}$ However, glucagon released from the former excites beta-cells which send GABA-inhibitory drive to alpha-cells. ${ }^{41}$ In addition to the above, it should be remembered that both adrenaline and glucagon are positively correlated with glucogenolysis and hyperglycemia both of which are absolutely minimized in the present research study.

According to all the above, we postulate that the postprandial hypoglycemic + insulinogenic effects provoked by the addition of a small dose of amantadine to the OGTT depends on peripheral + central nervous system mechanisms. The former should be attributed to the minimization of the inhibitory effect of circulating serotonin (plasma serotonin + platelet serotonin) plus the suppression of the glucogenolytic effect by adrenaline. At the central nervous system the above phenomena would depend on the inhibition of the $\mathrm{C}_{1}(\mathrm{Ad})$ medullary nuclei plus the absolute predominance of the $\mathrm{A}_{5}$ (NA) nucleus. Both insulin and glucagon cross the blood brain barrier and excite the $\mathrm{A}_{5}$ (NA) and the $\mathrm{C}_{1}$ (Ad) pontomedullary nuclei, respectively thus, the inhibition of the latter triggered by amantadine provoked the abrupt suppression of the adrenal glands secretion which favored the absolute predominance of the $\mathrm{A}_{5}$ (NA) neural sympathetic branch that resulted in the enhancement of insulin/glucagon ratio, registered in this study. This postulation receives definite support from overwhelming evidence quoted in several review articles and books. ${ }^{24,29,41,51,52}$

Summarizing all the above, it is possible to postulate that the hypoglycemic + hypoglucagonemic + insulinogenic effects triggered by the addition of amantadine to an oral glucose load would depend of both peripheral plus central nervous system mechanisms. The former should be associated to the minimization of the alpha-cells + adrenal glands secretion whereas the latter should be associated with the inhibition of the $\mathrm{C}_{1}$ (Ad) plus the disinhibition of the $\mathrm{A}_{5}$ (NA), responsible for the peripheral adrenal sympathetic and neural sympathetic branches axis, respectively.

\section{Disclosures}

The authors report no conflicts of interest in this work.

\section{References}

1. Göke B. Islet cell function: alpha and beta cells - partners towards normoglycaemia. Int J Clin Pract Suppl. 2008;(159):2-7.

2. Fanelli CG, Porcellati F, Rossetti P, Bolli GB. Glucagon: the effects of its excess and deficiency on insulin action. Nutr Metab Cardiovasc Dis. 2006;16(Suppl 1):528-534.

3. Cryer PE. Glucagon and hyperglycaemia in diabetes. Clin Sci (Lond). 2008;114(9):589-590.

4. Banerji MA. Impaired beta-cell and alpha-cell function in AfricanAmerican children with type 2 diabetes mellitus -"Flatbush diabetes" Pediatr Endocrinol Metab. 2002;15(Suppl 1):493-501.

5. Gelling RW, Vuguin PM, Du XQ, et al. Pancreatic beta-cell overexpression of the glucagon receptor gene results in enhanced beta-cell function and mass. Am J Physiol Endocrinol Metab. 2009;297(3):E695-E707.

6. Rizza RA, Cryer PE, Gerich JE. Role of glucagon, catecholamines, and growth hormone in human glucose counterregulation. Effects of somatostatin and combined alpha- and beta-adrenergic blockade on plasma glucose recovery and glucose flux rates after insulin-induced hypoglycemia. J Clin Invest. 1979;64(1):62-71.

7. Lam CK, Chari M, Lam TK. CNS regulation of glucose homeostasis. Physiology (Bethesda). 2009;24:159-170.

8. Lechin F, van der Dijs B, Benaim M. Stress versus depression. Prog Neuropsychopharmacol Biol Psychiat. 1996;20(6):899-950.

9. Lechin F, Coll-Garcia E, van der Dijs B, Bentolila A, Peña F, Rivas C. Effects of captivity on glucose tolerance in dogs. Experientia. 1979;35(7):876-877.

10. Lechin F, van der Dijs B, Pardey-Maldonado B, Baez S, Lechin ME. Effect of tianeptine on glucose tolerance with insulin secretion in human: Potential anti-diabetic effect of the drug. Open Neuroendocrinol J. 2009;2:10-19.

11. Lechin F, van der Dijs B, Lechin A, et al. Doxepin therapy for postprandial symptomatic hypoglycemic patients neurochemical, hormonal and metabolic disturbances. Clin Sci. 1991;80(4):373-384.

12. Lechin F, van der Dijs B. Haloperidol and insulin release. Diabetologia. 1981;20(1):78.

13. Lechin F, Coll-Garcia E, van der Dijs B, Bentolila A, Peña F, Rivas C. The effects of dopaminergic blocking agents on the glucose tolerance test in six humans and six dogs. Experientia. 1979;35(7):886-887.

14. Christensen NJ, Hilsted J, Egger M, Teuscher A, Frier BM, Hepburn DA. Plasma noradrenaline, human insulin, and hypoglycaemia. Lancet. 1989;334(8674):1268-1269.

15. Lechin F, van der Dijs B, Lechin M, et al. Effects of an oral glucose load on plasma neurotransmitters in humans: involvement of REM sleep? Neuropsychobiology. 1992;26(1-2):4-11.

16. Abdelmelek H, Fechtali T, Filali-Zegzouti Y, et al. Responsiveness of plasma catecholamines to intracerebroventricular injection of glucagon in Muscovy ducklings. J Neural Transm. 2001;108(7):793-801.

17. Fisher SJ, Brüning JC, Lannon S, Kahn CR. Insulin signaling in the central nervous system is critical for the normal sympathoadrenal response to hypoglycemia. Diabetes. 2005;54(5):1447-1451.

18. Dampney RA, Goodchild AK, Robertson LG, Montgomery W. Role of ventrolateral medulla in vasomotor regulation: a correlative anatomical and physiological study. Brain Res. 1982;249(2):223-235.

19. Byrum CE, Guyenet PG. Afferent and efferent connections of the A5 noradrenergic cell group in the rat. J Comp Neurol. 1987;261(4): $529-542$.

20. Loewy AD, Franklin MF, Haxhiu MA. CNS monoamine cell groups projecting to pancreatic vagal motor neurons: a transneuronal labeling study using pseudorabies virus. Brain Res. 1994;638(1-2): 248-260.

21. Loewy AD, Marson L, Parkinson D, Perry MA, Sawyer WB. Descending noradrenergic pathways involved in the A5 depressor response. Brain Res. 1986;386(1-2):313-324.

22. Loewy AD, Haxhiu MA. CNS cell groups projecting to pancreatic parasympathetic preganglionic neurons. Brain Res. 1993;620(2): $323-330$. 
23. Elenkov IJ, Wilder RL, Chrousos GP, Vizi ES. The sympathetic nerve - an integrative interface between two supersystems: the brain and the immune system. Pharmacol Rev. 2000;52(4):595-638.

24. Lechin F, van der Dijs B. Central nervous system circuitries underlying two types of peripheral autonomic nervous system disorders. Open Neurosci J. 2008;2:41-50.

25. Maiorov DN, Wilton ER, Badoer E, Petrie D, Head GA, Malpas SC. Sympathetic response to stimulation of the pontine A5 region in conscious rabbits. Brain Res. 1999;815(2):227-236.

26. Ross CA, Ruggiero DA, Park DH, et al. Tonic vasomotor control by the rostral ventrolateral medulla: effect of electrical or chemical stimulation of the area containing $\mathrm{C}_{1}$ adrenaline neurons on arterial pressure, heart rate, and plasma catecholamines and vasopressin. J Neurosci. 1984;4(2):474-494.

27. Morrison SF, Callaway J, Milner TA, Reis DJ. Rostral ventrolateral medulla: a source of the glutamatergic innervation of the sympathetic intermediolateral nucleus. Brain Res. 1991;562(1):126-135.

28. Zhou W, Fu LW, Tjen-A-Looi SC, Guo ZL, Longhurst JC. Role of glutamate in a visceral sympathoexcitatory reflex in rostral ventrolateral medulla of cats. Am J Physiol Heart Circ Physiol. 2006;291(3): H1309-H1318.

29. Lechin F, van der Dijs B. Crosstalk between the autonomic nervous system and the central nervous system: Mechanistic and therapeutic considerations for neuronal, immune, vascular, and somatic based diseases. In: Maiese K, editor. Neurovascular Medicine: Pursuing Cellular Longevity for Healthy Aging. New York, NY: Oxford University Press; 2009. p. 101-152.

30. Liu RH, Fung SJ, Reddy VK, Barnes CD. Localization of glutamatergic neurons in the dorsolateral pontine tegmentum projecting to the spinal cord of the cat with a proposed role of glutamate on lumbar motoneuron activity. Neuroscience. 1995;64(1):193-208.

31. Gerendai I, Halász B. Central nervous system structures connected with the endocrine glands. findings obtained with the viral transneuronal tracing technique. Exp Clin Endocrinol Diabetes. 2000;108(6): 389-395.

32. Kadish AH, Little RL, Sternberg JC. A new and rapid method for the determination of glucose by measurement of rate of oxygen consumption. Clin Chem. 1968;14:116-131.

33. Rowe JW, Young JB, Minaker KL, Stevens AL, Pallotta J, Landsberg L. Effect of insulin and glucose infusions on sympathetic nervous system activity in normal man. Diabetes. 1981;30(3):219-225.

34. Hegedüs L, Christensen NJ, Sestoft L. Abnormal regulation of sympathetic nervous activity and heart rate after oral glucose in type 1 (insulindependent) diabetic patients. Diabetologia. 1983;25(3):242-246.

35. Sun MK. Central neural organization and control of sympathetic nervous system in mammals. Prog Neurobiol. 1995;47(3):157-233.

36. Tanaka M, Matsumoto Y, Murakami T, Hisa Y, Ibata Y. The origins of catecholaminergic innervation in the rostral ventromedial medulla oblongata of the rat. Neurosci Lett. 1996;207(1):53-56.

37. Jacoby JH, Bryce GF. The acute pharmacologic effects of serotonin on the release of insulin and glucagon in the intact rat. Arch Int Pharmacodyn Ther. 1978;235(2):254-270.
38. Adeghate E, Ponery AS, Pallot D, Parvez SH, Singh J. Distribution of serotonin and its effect on insulin and glucagon secretion in normal and diabetic pancreatic tissues in rat. Neuro Endocrinol Lett. 1999;20(5):315-322.

39. de Leiva A, Tanenberg RJ, Anderson G, Greenberg B, Senske B, Goetz FC. Serotoninergic activation and inhibition: effects on carbohydrate tolerance and plasma insulin and glucagon. Metabolism. 1978;27(5):511-520.

40. Lechin F, van der Dijs B, Lechin M, et al. Plasma neurotransmitters throughout an oral glucose tolerance test in essential hypertension. Clin Exp Hypertens. 1993;15(1):209-240.

41. Lechin F, van der Dijs B. Central nervous system circuitry involved in the hyperinsulinism syndrome [review]. Neuroendocrinology. 2006;84(4):222-234.

42. Carvalho F, Barros D, Silva J, et al. Hyperglycemia induced by pharmacological activation of central serotonergic pathways depends on the functional integrity of brain CRH system and 5-HT3 receptors. Horm Metab Res. 2005;37(8):482-488.

43. Tobe T. Enterochromaffin cells and carcinoid syndrome. Nippon Rinsho. 1974;32(4):745-750.

44. Reynolds DJ, Leslie RA, Grahame-Smith DG, Harvey JM. Localization of 5-HT3 receptor binding sites in human dorsal vagal complex. Eur J Pharmacol. 1989;174(1):127-130.

45. Lechin F, van der Dijs B. Neuropharmacological therapy of carcinoid syndrome. Neuroendocrinology. 2005;81(3):137-138.

46. Lechin F, van der Dijs B. Intestinal pharmacomanometry and glucose tolerance: evidence for two antagonistic dopaminergic mechanisms in the human. Biol Psychiatry. 1981;16(10):969-971.

47. Lechin F, van der Dijs B. Glucose tolerance, non-nutrient drink and gastrointestinal hormones. Gastroenterology. 1981;80(1):216.

48. Lechin F, van der Dijs B, Orozco B. Cholecystokinin (CCK) and secretin and pancreatic secretion of insulin and glucagon. Dig Dis Sci. 2002;47(11):2422-2423.

49. Lechin F, van der Dijs B. Central nervous system circuitry and peripheral neural sympathetic activity responsible for essential hypertension. Curr Neurovasc Res. 2006;3(4):307-325.

50. Saito M, Saitoh T, Inoue S. Alpha 2-adrenergic modulation of pancreatic glucagon secretion in rats. Physiol Behav. 1992;51(6):1165-1171.

51. Lechin F, van der Dijs B, Hernandez-Adrian G. Dorsal Raphe (DR) vs Median Raphe (MR) serotonergic antagonism. Anatomical, physiological, behavioral, neuroendocrinological, neuropharmacological and clinical evidences: Relevance for neuropharmacological therapy. Prog Neuropsychopharmacol Biol Psychiatry. 2006;30(4): 565-585.

52. Lechin F, van der Dijs B, Lechin ME. Neurocircuitry and Neuroautonomic Disorders: Reviews and Therapeutic Strategies. Basel, Switzerland: Karger; 2002.

Diabetes, Metabolic Syndrome and Obesity: Targets and Therapy

Dovepress

\section{Publish your work in this journal}

Diabetes, Metabolic Syndrome and Obesity: Targets and Therapy is an international, peer-reviewed open-access journal committed to the rapid publication of the latest laboratory and clinical findings in the fields of diabetes, metabolic syndrome and obesity research. Original research, review, case reports, hypothesis formation, expert opinion and commentaries are all considered for publication. The manuscript management system is completely online and includes a very quick and fair peer-review system, which is all easy to use. Visit http://www.dovepress.com/testimonials.php to read real quotes from published authors. 